\title{
Design of Reactors for Bioremediation of Hydrocarbon Contaminated Water Bodies
}

Elelu, Madu Clement*, Amadi SA, Dagde KK and Iregbu PO

Department of Chemical / Petrochemical Engineering, Faculty of Engineering, Rivers State University, Nkpolu-Oroworukwo, Port Harcourt, Rivers State, Nigeria

\section{Article History}

Received: 05.08.2020

Accepted: 26.08 .2020

Published: 22.11.2020

Journal homepage:

https://www.easpublisher.com/

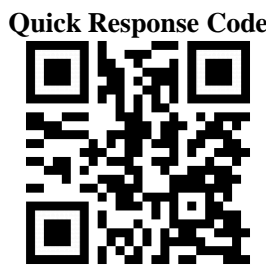

Abstract: The design models of isothermal batch and continuous stirred tank reactors are presented for bioremediation of crude oil in water environment. The reactor design equations were formulated based on conservation principle of mass and the reactor functional parameters simulated using MATLAB. The reactors were designed to treat crude oil at 95 to $99 \%$ degree of conversion with $79.5 \mathrm{~m}^{3}$ volume of crude oil in water required to be treated daily. The results obtained showed that residence time for the batch reactor increased with increase in crude oil removed, which took approximately 2 hours. In addition, the heat generated per unit volume decreases with increase in residence time, which ranged from $6594 \mathrm{~kJ} / \mathrm{h} \cdot \mathrm{m}^{3}$ to $6455 \mathrm{~kJ} / \mathrm{h} \cdot \mathrm{m}^{3}$ at residence time of 1.904 to 1.984 hours and 95 to $99 \%$ crude oil removal. Similarly, the CTSR results showed that the volume and space time increased with increase in crude oil removed. The volume of CSTR ranged from 6.722 to $9.209 \mathrm{~m}^{3}$, while space time ranged from 2.029 to 2.780 hours at 95 to $99 \%$ removal efficiency respectively. Conversely, the space velocity and heat generated per unit reactor volume decreased with increase in fractional conversion. The space velocity ranged from 0.493 to $0.36 \mathrm{~h}^{-1}$, while heat generated per unit reactor volume ranged from 1223 to $930.4 \mathrm{~kJ} / \mathrm{hr}^{3} \mathrm{~m}^{3}$ at 95 to $99 \%$ removal efficiency respectively. Hence, the time required to remove one volume of crude oil fed into the reactor was higher in CSTR compared to the batch reactor, and at $79.5 \mathrm{~m}^{3}$ of crude oil removal per day, the batch reactor will require 5 batches to complete the treatment. However, the heat generated per unit reactor volume was higher in batch reactor compared to the CSTR.

Keywords: Batch reactor, Bioremediation, Hydrocarbon contaminated water, Reactor design.

Copyright (C) 2020 The Author(s): This is an open-access article distributed under the terms of the Creative Commons Attribution 4.0 International License (CC BY-NC 4.0) which permits unrestricted use, distribution, and reproduction in any medium for non-commercial use provided the original author and source are credited.

\section{INTRODUCTION}

Crude oil is the world's most dependent resources, it aids or acts as source of energy to mechanized equipment or it acts as feed stock for many of the petrochemical industries. In 2003, crude oil was produced at 82.3 million barrels per day in volume. As at 2010 it was 101.6 million barrels per day. Hydrocarbon represents high volume of resources globally. Crude oil is a natural occurring complex mixture of hydrocarbon and non-hydrocarbon compounds which carry toxic substance harmful to human being. From the works of Obire et al. [1], the demand for crude oil as a resource for energy and a main source of industries has made an increase in its production, transportation and refining, which has resulted in gross pollution of the environment. However, crude oil and its petroleum derivatives also contain heavy metals. In the world today, water prospect causes shortages by population growth, uneven supplies of water, pollution and other criteria. The prediction done by United Nations that water shortages can retard the economic growth of most countries of the world, and had led to food shortages and possible conflicts.

Most water constitutes the main source of drinking water supply for humans. This water can serve for cooking, cleaning, industry and agriculture. These main sources of water that are supplied are polluted by natural geological sources, pesticides, industrial discharged from various processing industries and when oil spill during oil exploration and exploitation occurs. Most of these substances from crude oil are organic substances from products disposal into water bodies. These water bodies are contaminated and degraded that could possibly elevate the concentration levels of heavy metals. These heavy metals are persistent and can easily enter chain and accumulate until they reach toxic levels. Some of these heavy metals such as $\mathrm{Hg}, \mathrm{Cd}, \mathrm{Pb}, \mathrm{Co}$, $\mathrm{Mn}, \mathrm{Cu}, \mathrm{Fe}$ and $\mathrm{Cr}$ are contaminant to water which may affect human and ecosystem. Other causes of oil spills are known to have affected aquatic and terrestrial habitat. Petroleum as well as other products derived 
from it is shipped from oil-producing companies in various locations. The petroleum products are stored in vessels. Accidents due occurs for which the hulls of such vessels are damaged and their content spilled, and can cause damage to the water environment. Land and offshore oil wells also can be a source of oil spills into water bodies. When these oils spills, the accident may cause the oil to spread over water surface for example the Niger Delta area of Nigeria where there is increasing oil exploration and exploitation work. Vandalization of various pipeline carrying petroleum products results in oil spillage as well as petroleum products deposits into existing water bodies. This has become the order of the day. Also, the production, distribution, use, misuse, disposal or accidental spills of many chemicals have polluted the water bodies. These contaminations of water bodies have threatened the health of humans, livestock, wildlife and indeed whole ecosystems. Furthermore, cost used to restore the contaminated water bodies to healthy and accepted one is difficult. As a result, the agencies in government industries have actually felt the idea of better alternatives to physical and chemical methods of remediation of these contaminated water sites. Various researches have shown that there are various methods of bioremediation but different types of reactors would be used in this case [2]. A successful cost-effective bioremediation product is dependent on hydro geologic conditions, the contaminated water bodies and other spatial and temporal factors are varied. Microbial reactors are carried using microbial growth conditions to degrade population densities and presences of enzymes capable of destroying contaminants in the water bodies under controlled condition [3]. On the other hand, two main treatment properties for the

But the growth rate decay is expressed as:

$$
-r_{s}=\frac{\mu_{\max } S}{K_{s}+S}
$$

Where: $-r_{s}=$ Hydrocarbon degradation rate $\left(\mathrm{kmol} / \mathrm{m}^{3} \cdot \mathrm{h}\right), \mu_{\max }=$ Maximum specific rate constant $\left(\mathrm{kmol} / \mathrm{m}^{3} \cdot \mathrm{h}\right), K_{s}=$ Constant relating to Michaelis-Menten equation $\left(\mathrm{kmol} / \mathrm{m}^{3}\right) S=$ Substrate (hydrocarbon) concentration $\left(\mathrm{kmol} / \mathrm{m}^{3}\right)$

$$
S=S_{o}\left(1-X_{s}\right)
$$

Substitution of equations (2) into (1) yields:

$$
-r_{s}=\frac{\mu_{\max } S_{o}\left(1-X_{s}\right)}{K_{s}+S_{o}\left(1-X_{s}\right)}
$$

\section{Development of Reactor Performance Equations}

The reactor performance equation was developed in this section using the principle of mass removal of contaminant from water bodies are chemical and biological. The both processes would involve the use of the types of reactors, such as continuous stirred tank reactor. The treatment of the hydrocarbon contaminant in the water bodies would need the sizing or design of various reactors. The design would be compared to note which reactor size best suitable for the bioremediation processes. These micro-organisms would be cultured and hence a continuous stirred tank reactor or batch may rather be better than a plug flow reactor due to its gaseous applications. In order to treat hydrocarbon contaminant, chemical or biological are employed. The main advantages chemical treatment has over the biological processes or treatment are mineralization of non-biodegradable compounds and smaller reactor volume when the advantages gives results, the disadvantages are also there [4].

\section{Materials ANd Methods Materials}

The design equation for the reactor types was developed in this chapter. The resulting equations were used for the simulation of the reactor functional parameters implemented with MATLAB Simulink.

\section{Rate Kinetic Expression}

Most studies on crude oil remediation have been focused on the development of the kinetic rate, which proposed the first order rate kinetics as the best fit model that described crude oil removal in contaminated environment [5]. Here, the MichaelisMenten model was adopted, as it is one of the models that have been used for bioremediation studies [6, 7]. The Michaelis-Menten rate equation is expressed as:

Meanwhile, to equation (1) can be expressed in terms of conversion using the relationship between the initial and instantaneous substrate concentrations according to Levenspiel (2004) as follows.

conservation, and it is expressed as shown in equation (4). 


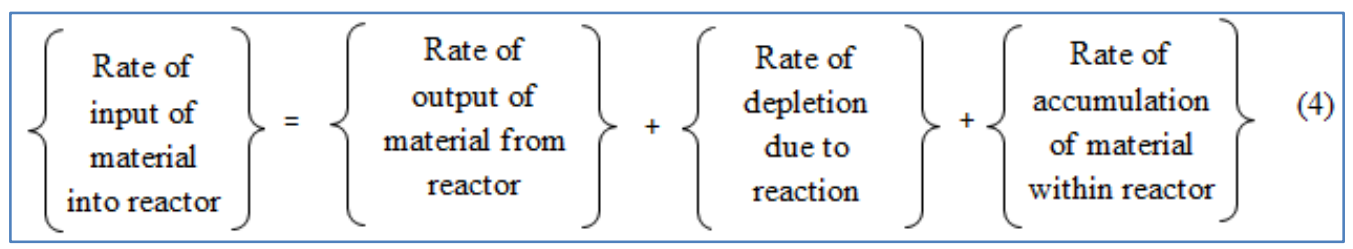

\section{Material Balance on Batch Reactor}

A schematic diagram of batch reactor is shown in Figure 1. In a batch reactor, the raw materials are charged into the reactor at once and allowed to react until the reaction is complete; the product withdrawing before charging in new feed.

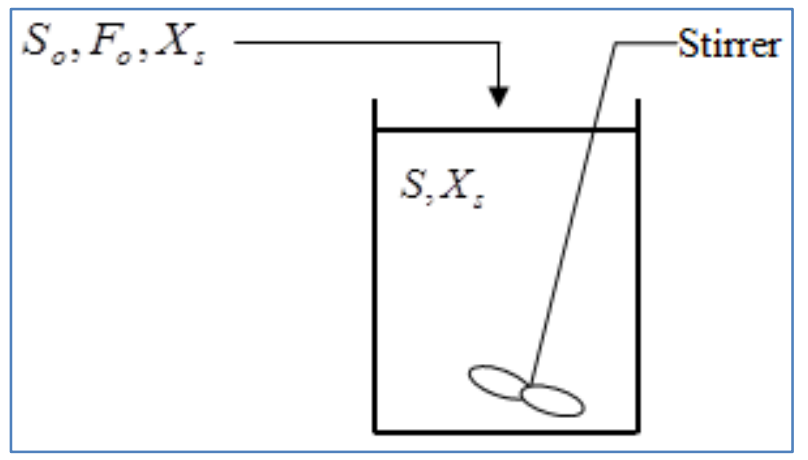

Fig-1: Schematic Batch Reactor with Stirrer

From the material balance model in equation 4 :

$$
F_{o}=F+\left(-r_{s}\right) V_{\text {Batch }}+\frac{d N_{s}}{d t}
$$

Simplifying equation 5 and taking into consideration that for batch reactor, $F_{o}=F=0$, we have;

$$
S_{o} \frac{d X_{s}}{d t}=\left(-r_{s}\right)
$$

So, substituting the rate term in equation (3) into (6) gives:

$$
S_{o} \frac{d X_{s}}{d t}=\frac{\mu_{\max } S_{o}\left(1-X_{s}\right)}{K_{s}+S_{o}\left(1-X_{s}\right)}
$$

Where: $S_{o}=$ Initial concentration of crude oil $\left(\mathrm{mol} / \mathrm{m}^{3}\right), S=$ Instantaneous concentration of crude oil $\left(\mathrm{mol} / \mathrm{m}^{3}\right), F_{o}=$ Inlet flow rate $\left(\mathrm{m}^{3} / \mathrm{s}\right), F=$ Outlet flow rate $\left(\mathrm{m}^{3} / \mathrm{s}\right), V=$ Volume of reactor $\left(\mathrm{m}^{3}\right), N_{s}=$ Amount of crude oil $(\mathrm{kmol}), t=$ Time of remediation (s)

\section{Heat Generated per unit Volume of Batch Reactor}

The heat generated in batch reactor is given according to Ukpaka, (2019) as

$$
q_{\text {Batch }}=\frac{Q}{V_{\text {Batch }}}
$$

But for batch reactor, since there is no flow of materials, therefore,

$$
Q=\left(-\Delta H_{r}\right) \frac{N_{s o}}{t} X_{s}
$$


Substituting equation (9) into (8) gives:

$$
q_{\text {Batch }}=\frac{\left(-\Delta H_{r}\right) N_{s o} X_{s}}{t V_{\text {Batch }}}
$$

\section{Material Balance on Continuous Stirred Tank} Reactor (CSTR)

The schematic diagram of CSTR is shown in

Figure 2. In CSTR, there is inflow and outflow of materials. The performance equation of CSTR was developed using equation

(4) as follows.

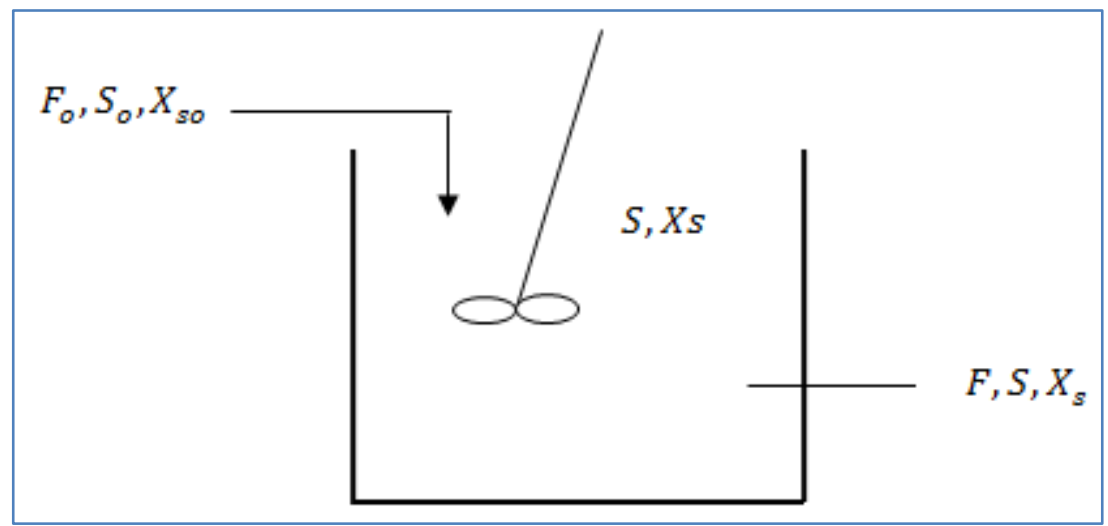

Fig-2: Continuous Stirred Tank Reactor

From equation (4) we have:

$$
F_{o}=F+\left(-r_{s}\right) V_{C S T R}+\frac{d N_{s}}{d t}
$$

Simplifying at steady state condition: and taking into consideration that for a CSTR, $\frac{d N_{s}}{d t}=0$ we have;

\section{Volume of CSTR}

From equation (11), the volume of CSTR was obtained as:

$$
V_{C S T R}=\frac{F_{o} X_{s}}{\left(-r_{s}\right)}
$$

Substitution of equation (3) into (11) gives

$$
V_{C S T R}=\frac{F_{o} X_{s}\left[K_{s}+S_{o}\left(1-X_{s}\right)\right]}{\mu_{\max } S_{o}\left(1-X_{s}\right)}
$$

\section{Height of CSTR}

The height of a cylindrical shape CSTR is given as

$$
H_{C S T R}=\frac{V_{C S T R}}{\pi D^{2}}
$$

Hence upon substitution of equation (13) into (14), yields

$$
H_{C S T R}=\frac{F_{o} X_{s}\left[K_{s}+S_{o}\left(1-X_{s}\right)\right]}{\pi D^{2} \mu_{\max } S_{o}\left(1-X_{s}\right)}
$$




\section{Space Time of CSTR}

This is mathematically expressed according to Levenspiel [8] as:

$$
S_{T}=\frac{V_{C S T R}}{v_{0}}
$$

Substituting equation (13) into equation (16) yields:

$$
S_{T}=\frac{F_{o} X_{s}\left[K_{s}+S_{o}\left(1-X_{s}\right)\right]}{v_{o} \mu_{\max } S_{o}\left(1-X_{s}\right)}
$$

\section{Space Velocity of CSTR}

This is defined as the number of reactor volume of feed that can be treated in a unit time at specified condition [8] and it is expressed as

$$
S_{v}=\frac{v_{0}}{V_{C S T R}}
$$

Substituting equation (13) into equation (18) yields

$$
S_{v}=\frac{v_{o} \mu_{\max } S_{o}\left(1-X_{s}\right)}{F_{o} X_{s}\left[K_{s}+S_{o}\left(1-X_{s}\right)\right]}
$$

\section{Heat Generated per unit Volume of CSTR}

The heat generated per unit volume of CSTR is expressed as:

$$
q_{C S T R}=\frac{Q}{V_{C S T R}}
$$

But the total heat generated in the CSTR can be expressed as:

$$
Q=\left(-\Delta H_{r}\right) F_{o} X_{s}
$$

Hence upon substitution of equations (13) and (21) into (3.33) gives:

$$
q_{\text {CSTR }}=\frac{\left(-\Delta H_{r}\right) v_{o} \pi R^{2} \mu_{\max } S_{o}\left(1-X_{s}\right)}{K_{s}+S_{o}\left(1-X_{s}\right)}
$$

Equations (7) and (10) of the batch reactor model is a complex non-linear equation. So, to obtain solution to the model, the Runge-Kutta algorithm is

$$
S(i+1)=S(i)+\left[k_{1}+2\left(k_{2}+k_{3}\right)+k_{4}\right] / 6
$$

where:

$$
\begin{aligned}
& k_{1}=h f(t(i), S(i)) \\
& k_{2}=h f\left(t(i)+\frac{1}{2} h, S(i)+\frac{1}{2} k_{1}\right) \\
& k_{3}=h f\left(t(i)+\frac{1}{2} h, S(i)+\frac{1}{2} k_{2}\right) \\
& k_{4}=h f\left(t(i)+h, S(i)+k_{3}\right) \\
& h=\text { Step size }
\end{aligned}
$$

used and solved in MATLAB. The algorithm for Runge-Kutta is expressed as follows [9]. 


$$
k_{1}, k_{2}, k_{3}, k_{4}=\text { Constants }
$$

\section{Design Operating Parameters}

The reactors were designed to treat 500 barrel of crude oil per day in contaminated water at $95 \%$ to 99\% conversion (removal) of crude oil. However, the following operating parameters are necessary to achieve the design.

$$
\frac{0.159 m^{3}}{l b} \times 500 l b=79.5 m^{3}
$$

Therefore, the volumetric flow rate $v_{o}=\frac{79.5 \mathrm{~m}^{3}}{d a y} \times \frac{d a y}{24 h}=3.3125 \mathrm{~m}^{3} / \mathrm{h}$

\section{Initial Concentration of Crude Oil}

The initial molar concentration of the crude oil can be estimated using the formula:

$$
S_{o}=\frac{\rho_{o}}{M_{w o}}
$$

Where: $S_{o}=$ Initial crude oil concentration $\left(\mathrm{kmol} / \mathrm{m}^{3}\right), \frac{\rho_{o}}{M_{w o}}$ Crude oil molar density $\left(\mathrm{kg} / \mathrm{m}^{3}\right), M_{w o}=\mathrm{Molecular}$ weight crude oil $(\mathrm{kg} / \mathrm{kmol})$

The Bonny Light Crude Oil (BLCO) was selected as a case study, and its API gravity and density are given as $32.9^{\circ} \mathrm{API}$ and $860 \mathrm{~kg} / \mathrm{m}^{3}[10]$.

Similarly, the molecular weight of crude oil can be estimated using Cragoe correlation [11]. This correlation is expressed as:

$$
M_{w o}=\frac{6084}{{ }^{o} A P I-5.9}
$$

Here, the molecular weight is expressed in lb/lb-mol. Upon substitution of the API gravity (32.9), we obtain the molecular weight of the crude oil as follows.

$$
M_{w o}=\frac{6084}{32.9-5.9}=225.331 \mathrm{~b} / \mathrm{lb}-\mathrm{mol}
$$

But, $1 \mathrm{lb} \equiv 0.45359237 \mathrm{~kg}$ and $1 \mathrm{lb}-\mathrm{mol} \equiv 0.45359237 \mathrm{kmol}$

Therefore, in metric unit, we have:

$$
M_{w o}=\left(\frac{0.45359237 \mathrm{~kg}}{\mathrm{lb}} \times \frac{\mathrm{lb} / \mathrm{lb}-\mathrm{mol}}{\mathrm{kmol}}\right) \times 225.33 \frac{\mathrm{lb}}{\mathrm{lb} / \mathrm{lb}-\mathrm{mol}}=102.209 \mathrm{~kg} / \mathrm{kmol}
$$
follows.

So, substituting the corresponding values into equation (28) the initial crude concentration was calculated as

$$
S_{o}=\frac{860 \mathrm{~kg} / \mathrm{m}^{3}}{102.209 \mathrm{~kg} / \mathrm{kmol}}=8.414 \mathrm{kmol} / \mathrm{m}^{3}
$$

\section{Molar Flow Rate}

The molar flow rate of the crude oil into CSTR can be estimated using the formula:

$$
F_{o}=S_{o} v_{o}
$$


Substituting the initial crude concentration and the volumetric flow rate gives as follows.

$$
F_{o}=8.414 \mathrm{kmol} / \mathrm{m}^{3} \times 3.3125 \mathrm{~m}^{3} / \mathrm{h}=27.872 \mathrm{kmol} / \mathrm{h}
$$

\section{Amount in Mole}

The amount of crude required to be charged into reactor can be calculated from the molecular weight, volume and the density relation given by the formula in equation (31).

$$
N_{s o} \frac{\rho_{o} V}{M_{w o}}
$$

By substitution, we have:

$$
N_{s o}=\frac{860 \mathrm{kgm}^{-3} \cdot \times 79.5 \mathrm{~m}^{3}}{102.209 \mathrm{~kg} \cdot \mathrm{kmol}^{-1}}=668.92 \mathrm{kmol}
$$

The summary of input parameters used for the analysis of the reactor functional parameters is presented in Table 1 .

Table-1: Summary of Input Parameters

\begin{tabular}{|l|l|l|}
\hline Parameter & Value & Reference \\
\hline Initial concentration, $S_{o}\left(\mathrm{kmol} / \mathrm{m}^{3}\right)$ & 102.209 & Calculated \\
\hline Volumetric flow rate $\left(\mathrm{m}^{3} / \mathrm{h}\right)$ & 3.3125 & Calculated \\
\hline Heat of reaction, $\Delta H_{r}(\mathrm{~kJ} / \mathrm{kmol})$ & 310.5 & Assumed \\
\hline Molar flow rate, $F_{o}(\mathrm{kmol} / \mathrm{h})$ & 27.872 & Calculated \\
\hline Maximum specific rate constant, $\mu_{\max }\left(\mathrm{kmol} / \mathrm{m}^{3} \mathrm{~h}\right)$ & 4.275 & Najafpour [12] \\
\hline Rate constant, $K_{s}\left(\mathrm{kmol} / \mathrm{m}^{3}\right)$ & 0.0359 & Najafpour [12] \\
\hline
\end{tabular}

\section{RESUlTS AND DiSCUSSION}

The performances of batch reactor and continuous stirred-tank reactor for bioremediation of hydrocarbon contaminated water at isothermal condition have been investigated. The design models developed for the reactor types were simulated using computer program developed using MATLAB programme compiler and the results are presented below. Although, the reactor operation mechanisms are not the same, the heat generated per reactor volume obtained from the reactors as well the residence time was compared. Thus, for residence time comparison, the batch time for batch reactor and space time for CSTR were used as basis for comparing the time it takes to treat one volume of crude oil fed into the reactor.

\section{Batch Reactor Result}

The simulated results obtained from the batch reactor analysis were presented in Figures 3 to 6 . Time is an important indicating parameter in the operation of batch reactor. Therefore, the time to remove a given fraction of crude oil during treatment process was investigated at $95 \%$ to $99 \%$ degree of crude oil conversion. It is worthy of note however, that the batch reactor size was kept constant throughout the simulation since the feed in batch reactor is fed into the reactor once and the product withdrawn only after the reaction has attain completion. Also, the reactor was operated at ambient temperature. 


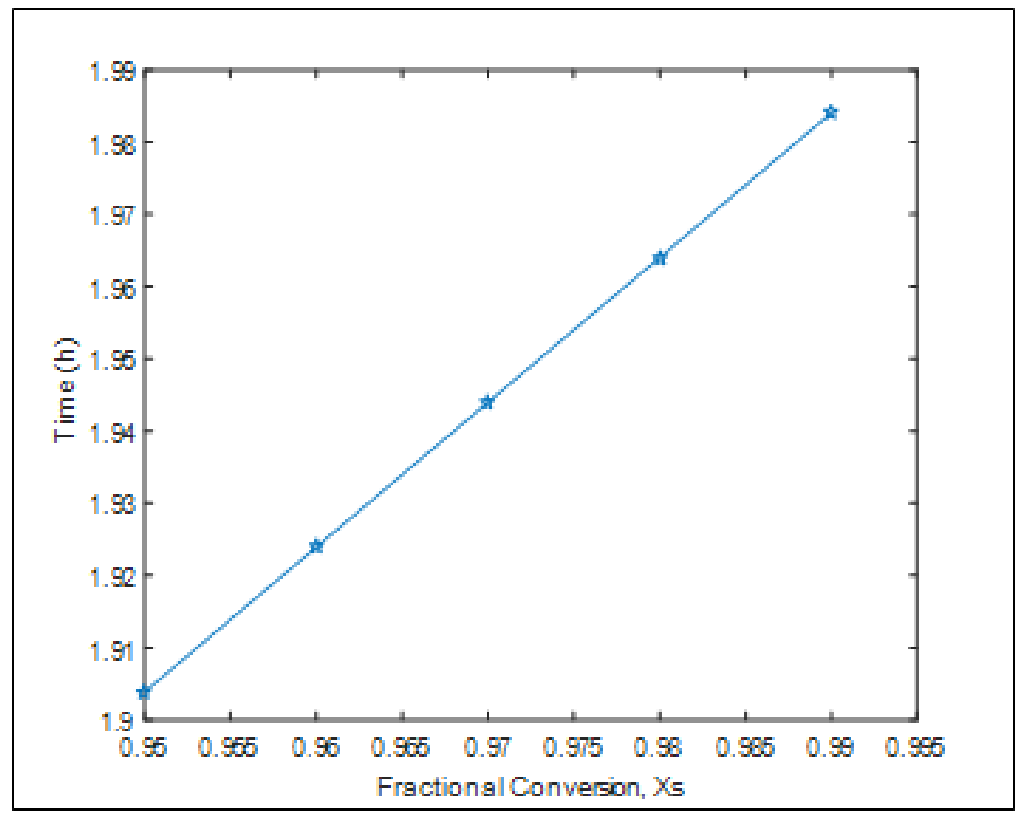

Fig-3: Influence of Degree of Conversion on Batch Time

The time required to treat or remove crude oil initially charged into the batch reactor was analyzed at different desired fractions of crude oil required to be removed from the contaminated water at constant reactor volume. Figure 3 shows the variation of batch time with respect to change in the desired fraction of crude oil removal (fractional conversion) from the contaminated water. It was revealed that increase in crude oil fraction conversion correspondingly increases the batch time. From the profile, the relationship between time and conversion of crude oil in batch reactor can best be described as linear. It can be inferred that the time required to treat crude oil in contaminated environment is approximately 2 hours. Although, Afzal, et al., [13] did not used batch reactor, but obtained $99.1 \%$ of removed hydrocarbon in water in their floating treatment design technique. However, the time required for this method of treatment was greater than the values obtained in this work.

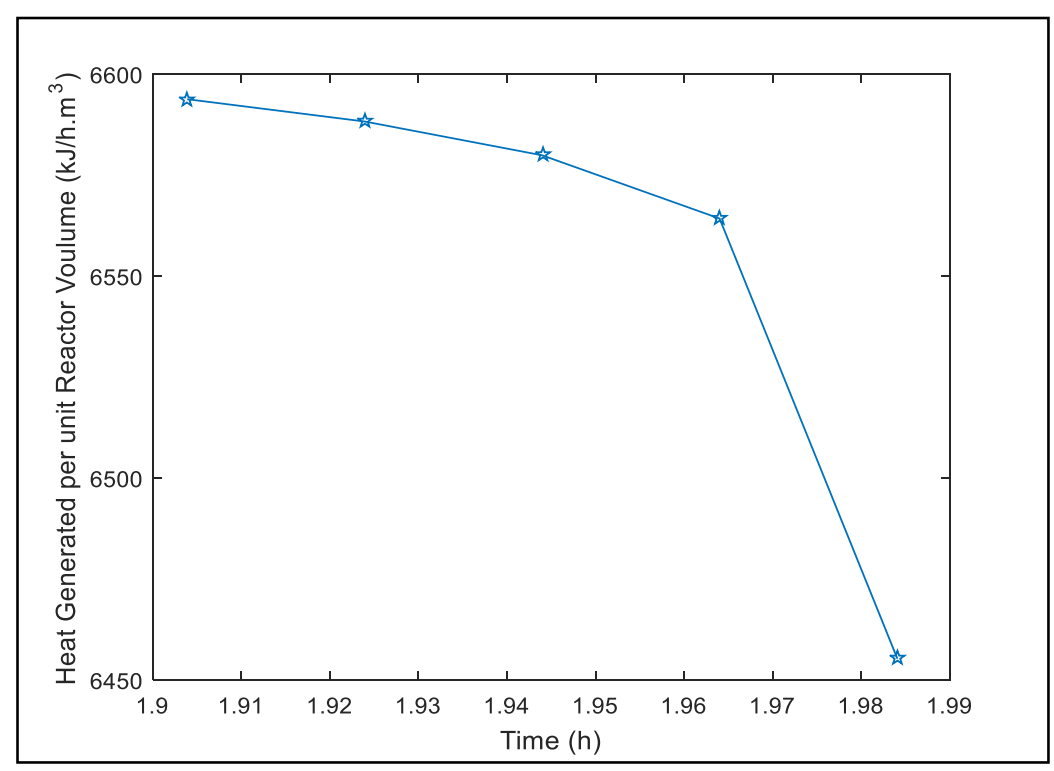

Fig-4: Heat Generated per unit Volume versus Batch Time 


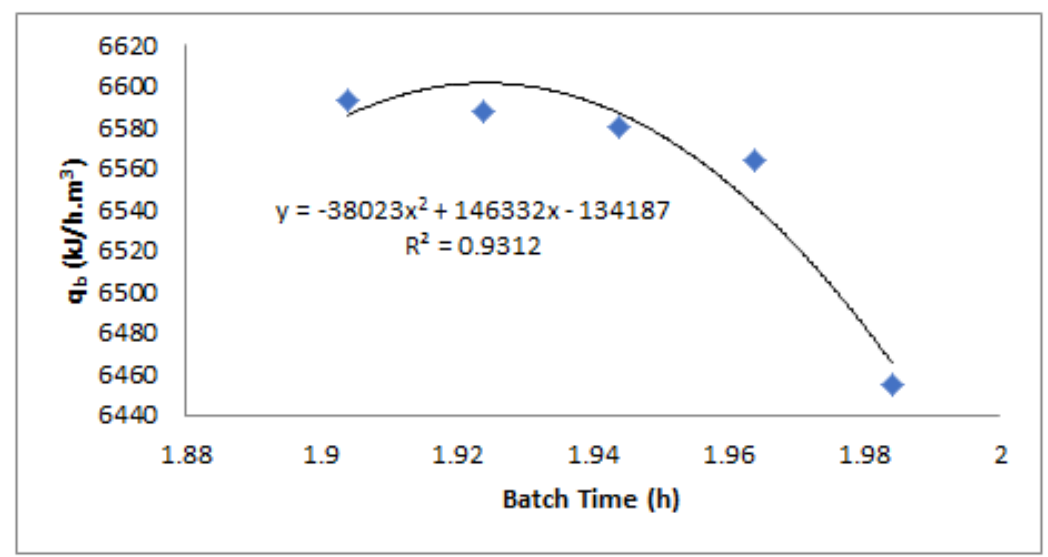

Fig-5: Relationship between Heat Generated per unit Volume and Treated Crude

The profile of heat generated per volume of batch reactor against batch time is shown in Figure 5 . The simulated results show that increasing the batch time causes a decrease in the heat generated per volume of the batch reactor. Although, within 95 to $99 \%$ removal of the crude oil, the increase in batch time was not significant as this was also observed for the heat generation. However, the heat generated per volume of the batch reactor was obtained between $6594 \mathrm{~kJ} / \mathrm{h} . \mathrm{m}^{3}$ and $6455 \mathrm{~kJ} / \mathrm{h} \cdot \mathrm{m}^{3}$ at the range of batch time of 1.904 to 1.984 hours. Meanwhile, the relationship between the heat generated per unit volume of batch reactor and the batch time can be described as a quadratic function, as shown in Figure 5 with correlation coefficient $R^{2}$ given as 0.9312 . The low values of heat generation recorded may be due to the fact that the reactor was operated at ambient temperature.

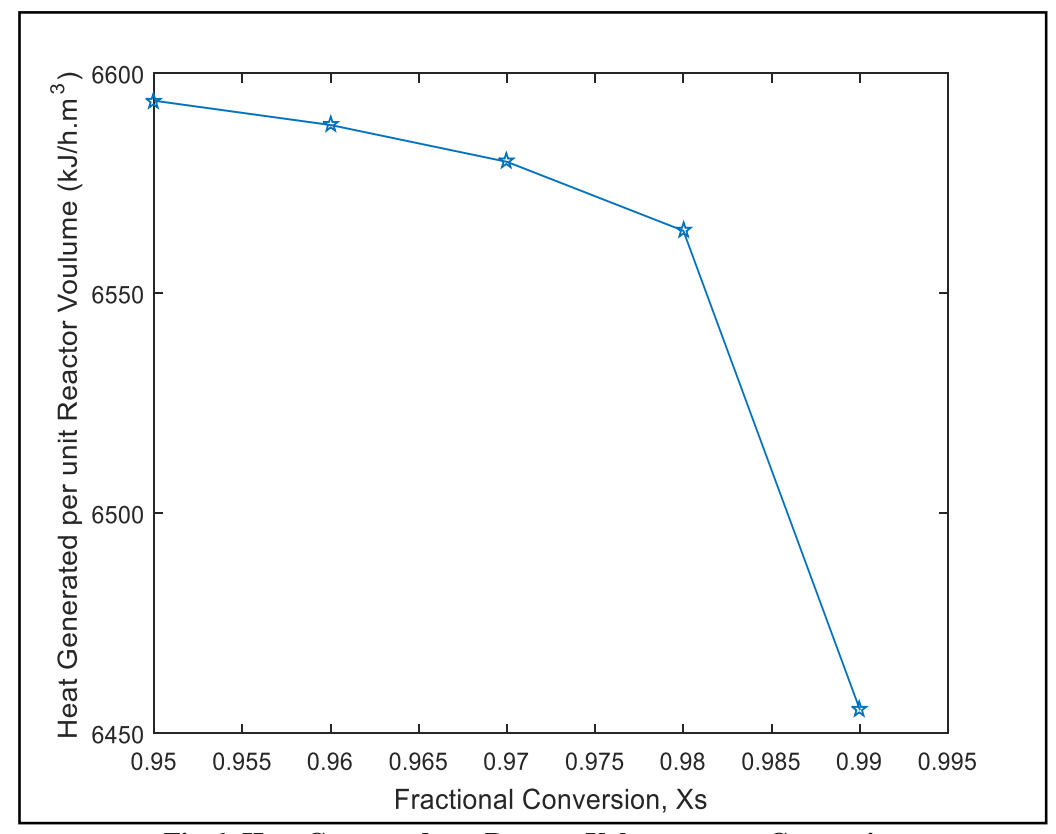

Fig-6: Heat Generated per Reactor Volume versus Conversion

Figure 6 shows the heat generated per volume of the batch reactor versus the fraction of crude oil removed. Like in batch time, the rate of heat generation per the reactor volume decreases as the fraction of crude oil desired to be removed by reactor increases. This implies that operating the reactor at high removal efficiency will reduce the amount of heat generation because of the constant temperature operation. In Ukpaka, [14], the heat generated per batch reactor volume increased with batch time as the reactor was operated at non-isothermal condition .He further stated that, to achieve higher conversion, more heat will be generated per volume of the reactor However, the heat generated per volume of the batch reactor was obtained between $6594 \mathrm{~kJ} / \mathrm{h} \cdot \mathrm{m}^{3}$ and $6455 \mathrm{~kJ} / \mathrm{h} \cdot \mathrm{m}^{3}$ at the desired 95 to $99 \%$ hydrocarbon removal.

\section{Continuous Stirred-Tank Reactor Result}

The simulated results obtained from the analysis of the continuous stirred-tank reactor are shown and discussed as presented in Figures 7 to 10 . The CSTR results include size, space time, space velocity and heat generated per reactor volume at isothermal condition. 


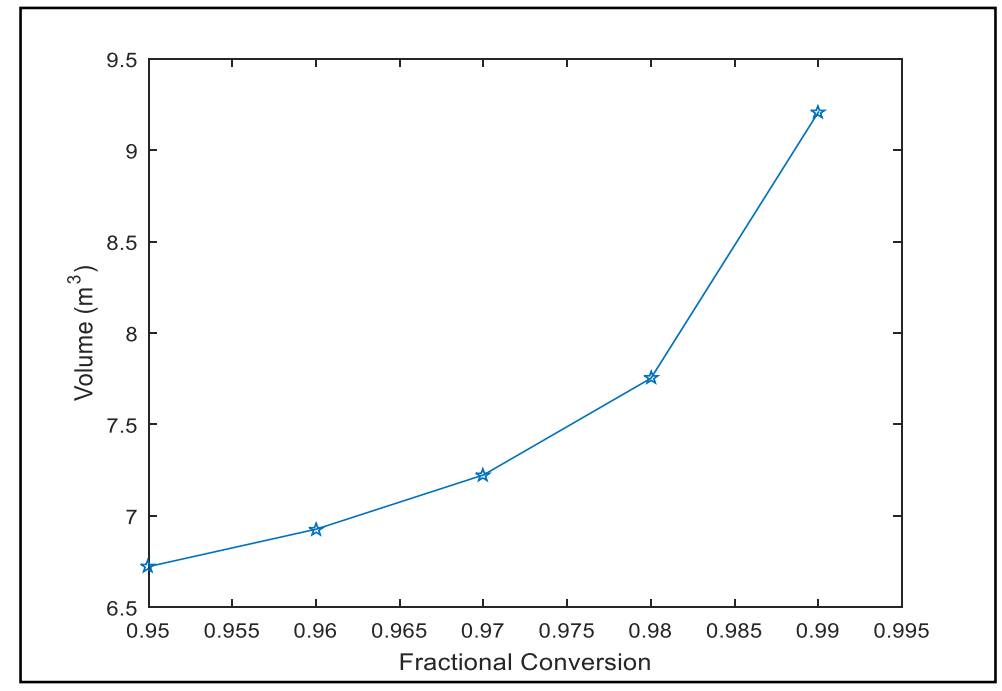

Fig-7: Volume of CSTR versus Conversion

Figure 7 shows the profile of CSTR volume versus the desired fractional conversion of crude oil. As the desired fraction of the crude oil removal was increased, the reactor volume also increased exponentially. This follows that to achieve a high removal of the hydrocarbon in CSTR, the volume of reactor and hence, the size will be required to increase. From the graph, the volume of CSTR obtained at $95 \%$ was $6.722 \mathrm{~m} 3$, while at $99 \%$ it was $9.209 \mathrm{~m}^{3}$.

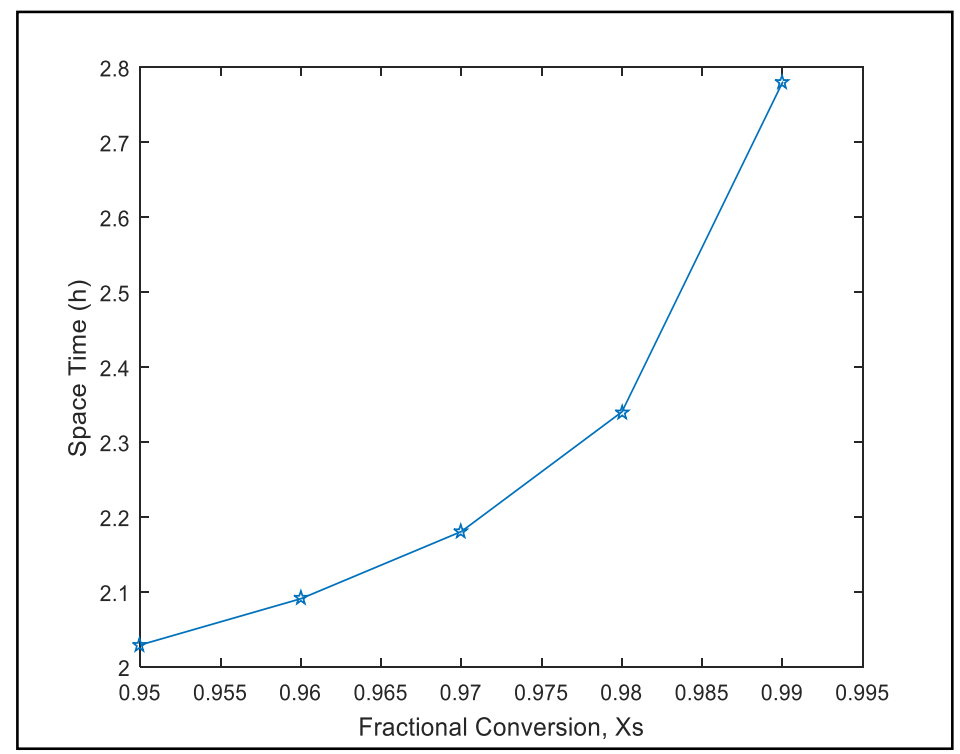

Fig-8: Space Time versus Conversion

Figure 8 shows the space time of CSTR versus fractional conversion. The space time of CSTR increases as fractional conversion of the crude oil was increased. Like volume, higher time will be required to treat one reactor volume of crude oil at higher conversion. From the analysis, the CSTR space time obtained at $95 \%$ was 2.029 hours, and at $99 \%$ it was obtained as 2.780 hours. This implied that between 2 and 3 hours, the CSTR would remove not less than 95 to 99 percentage of initially charged volume of crude oil in contaminated water. 


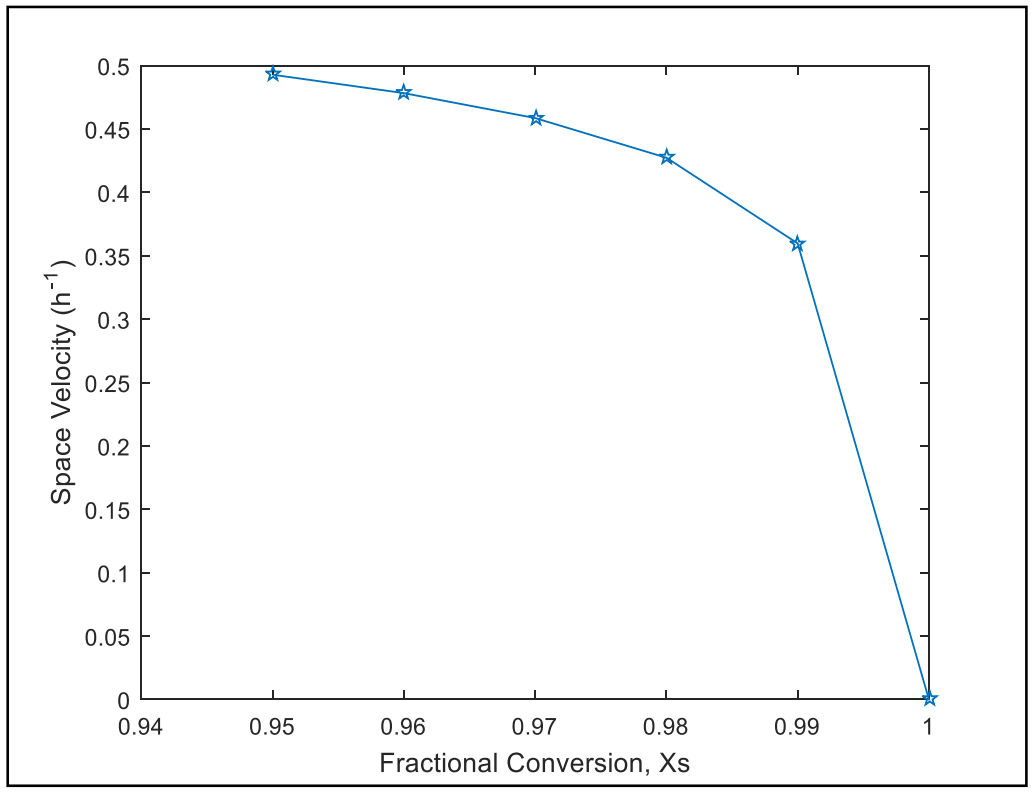

Fig-9: Space Velocity versus Conversion

Figure 9 shows the profile of space velocity of CSTR versus fractional conversion. As demonstrated in the figure, space velocity decreases non-linearly as removal efficiency was increased. This implies that fewer number of reactor volume of the crude oil fed into the reacted will be treated per hour at higher degree of conversion. Again, from the analysis, space velocity obtained at $95 \%$ was $0.493 \mathrm{~h}^{-1}$, and at $99 \%$ it was obtained as $0.36 \mathrm{~h}^{-1}$.

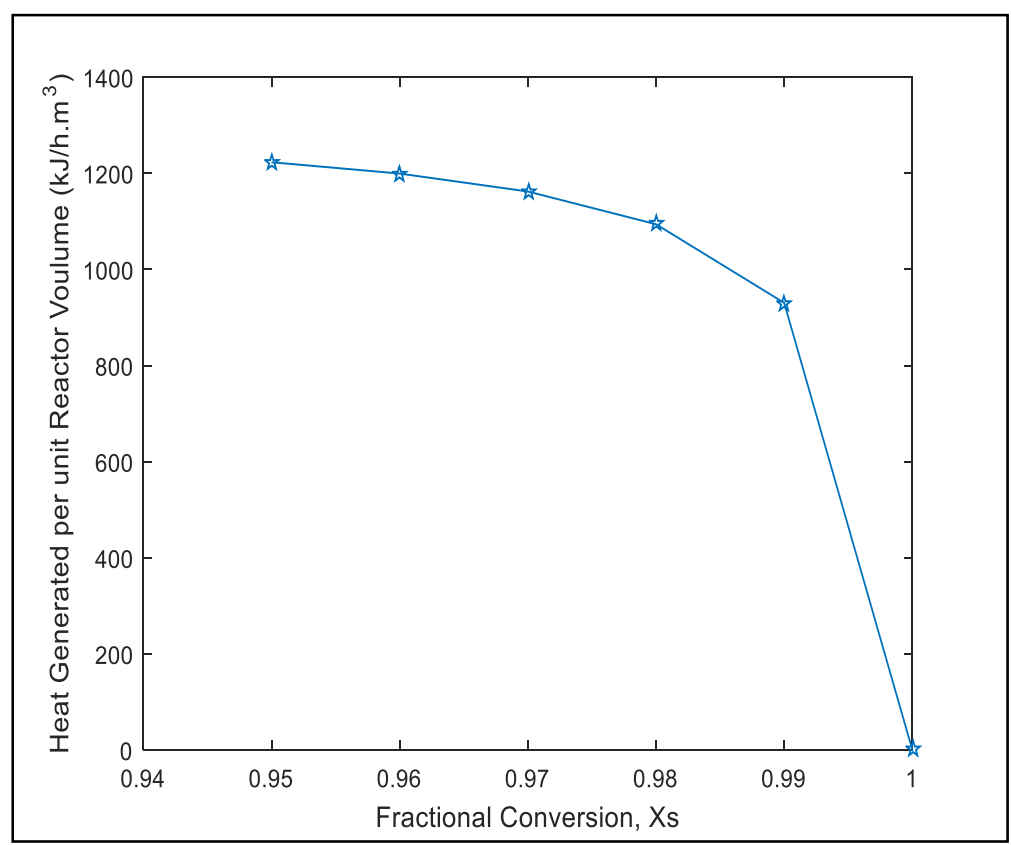

Fig-10: Heat Generated per CSTR Volume versus Conversion

Figure 10 shows the profile of heat generated per reactor volume of CSTR versus desired crude oil conversion. Like the CSTR space velocity, the heat generated per reactor volume of CSTR decreases as the conversion was increased. Thus, the heat generated per reactor volume of CSTR obtained at $95 \%$ crude oil removal was $1223 \mathrm{~kJ} / \mathrm{hr}^{3} \mathrm{~m}^{3}$, while $930.4 \mathrm{~kJ} / \mathrm{hr}^{3} \mathrm{~m}^{3}$ was obtained at $99 \%$ crude oil removal.
Comparison of Functional Parameters of the Reactor Types

The residence time and heat generation per reactor volume for the reactors were compared with respect to conversion as shown in Figures 11 and 12. 


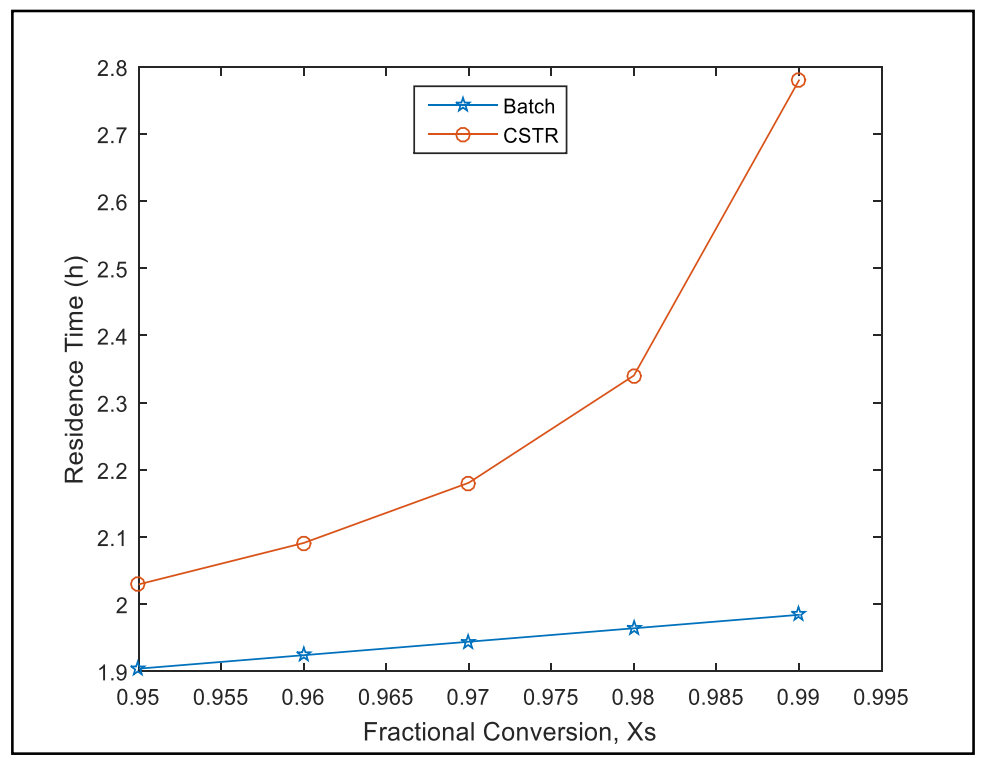

Fig-11: Comparison of Residence Time of the Reactor Types

Figure 11 shows the profiles for comparison of residence time (space time for CSTR and batch time for batch reactor) at the same operational conditions. From the profiles, it can be seen that the time required to remove one volume of crude oil fed into the reactor was higher in CSTR compared to the batch reactor. While the CSTR process was continuous, the batch was not. Thus, at $99 \%$ conversion the residence time for batch and CSTR are $1.984 \mathrm{~h}$ and $2.780 \mathrm{~h}$. Meanwhile, at $79.5 \mathrm{~m}^{2}$ batch reactor volume, it will require 5 batches to complete the treatment of the designed volume of crude oil per day. However, this is not the case for CSTR, as the process will only stop after the completion of treatment. So, the batch reactor requires larger volume than the CSTR.

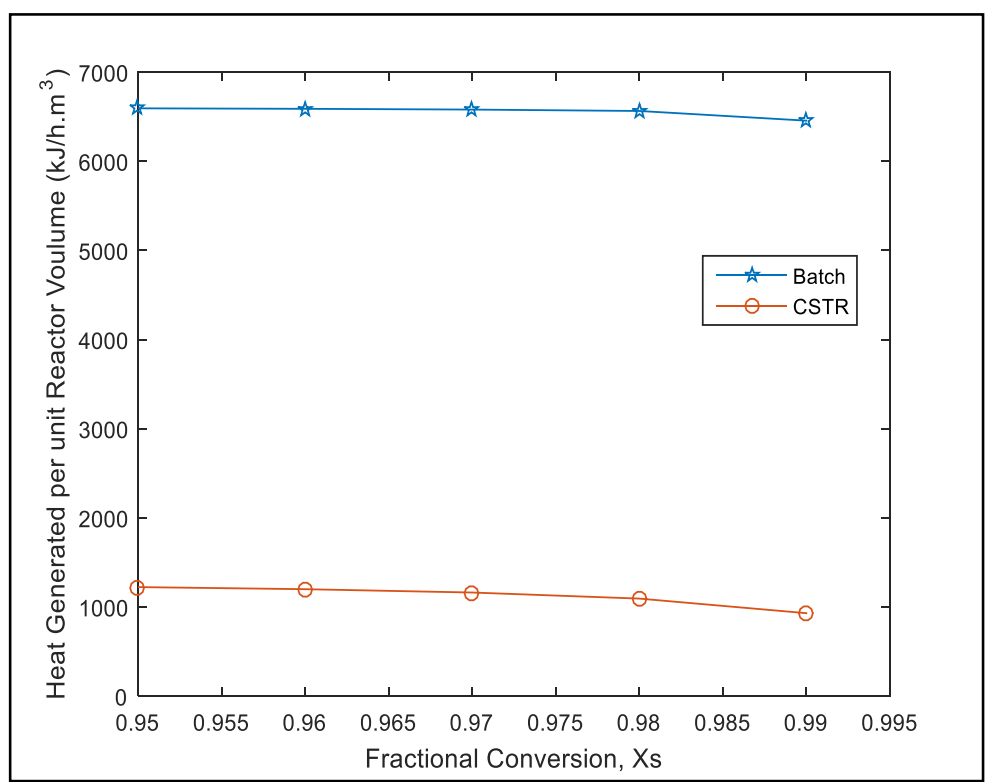

Fig-12: Comparison of Heat Generated per unit Volume of the Reactor Types

The comparison of heat generated per reactor volume of the reactor types is shown in Figure 12. Thus, heat generated per reactor volume for the reactor was higher in batch reactor compared to CSTR. This is a reverse of residence time. This high variation in the heat generation per reactor volume was due to the smaller size of CSTR, which required lesser heat to be generated per reactor volume compared to the batch reactor. For instance, at $99 \%$ crude oil removal, the heat generated per reactor volume was obtained as $64552 \mathrm{~kJ} / \mathrm{h} \cdot \mathrm{m}^{3}$ and $930.4 \mathrm{~kJ} / \mathrm{h} \cdot \mathrm{m}^{3}$ for batch reactor and CSTR respectively. 
Table-2: Summary of Reactor Design Parameters

\begin{tabular}{|l|l|l|}
\hline Parameters & Batch Reactor & CSTR \\
\hline Temperature (K) & Ambient & Ambient \\
\hline Batch Time (h) & $1.90-1.98$ & N/A \\
\hline Conversion $(\%)$ & $95-99$ & $95-99$ \\
\hline Diameter (m) & 1.20 & 1.20 \\
\hline Volume $\left(\mathrm{m}^{3}\right)$ & 15.9 (constant) & $6.72-9.21$ \\
\hline Height/Length (m) & 3.51 & $1.49-2.04$ \\
\hline Space Time (hr) & N.A & $2.03-2.78$ \\
\hline Space Velocity $\left(\mathrm{hr}^{-1}\right)$ & N.A & $0.49-0.36$ \\
\hline Heat Generated per unit Volume (kJ/h.m $\left.{ }^{3}\right)$ & $6594-6455$ & $1223-930.4$ \\
\hline
\end{tabular}

\section{CONCLUSION}

Design equations for batch and continuous stirred tank reactor (CSTR) have been performed for bioremediation of crude oil in water environment at isothermal condition. The design equations were solved and simulated using MATLAB to facilitate the analysis of the reactor functional parameters. The reactors were designed to treat crude oil at 95 to $99 \%$ degree of conversion with $79.5 \mathrm{~m}^{3}$ volume of crude oil in water required to be treated per day. From the results, the batch time increases with increase in the amount of crude oil removed, which was approximately 2 hours. Also, the heat generated per unit volume for batch reactor decreases with increase in batch time, which ranged from $6594 \mathrm{~kJ} / \mathrm{h} \cdot \mathrm{m}^{3}$ to $6455 \mathrm{~kJ} / \mathrm{h} \cdot \mathrm{m}^{3}$ at batch time of 1.904 to 1.984 hours and 95 to $99 \%$ crude oil removal. Similarly, the CTSR results showed that the volume and space time increased exponentially as fractional conversion increased. Hence, larger reactor size and space time are required to achieve high removal of hydrocarbon in water. The volume of CSTR ranged from 6.722 to $9.209 \mathrm{~m}^{3}$, while space time ranged from 2.029 to 2.780 hours at 95 to $99 \%$ removal efficiency respectively. However, the space velocity and heat generated per unit reactor volume decreases with increase in fractional conversion. Similarly, space velocity ranged from 0.493 to $0.36 \mathrm{~h}^{-1}$, while heat generated per unit reactor volume ranged from 1223 to $930.4 \mathrm{~kJ} / \mathrm{hr}^{3} \mathrm{~m}^{3}$ at 95 to $99 \%$ removal efficiency respectively. Conclusively, the time required to remove one volume of crude oil fed into the reactor was higher in CSTR compared to the batch reactor. At the $79.5 \mathrm{~m}^{3}$ of crude oil removal per day, the batch reactor will require 5 batches to complete the treatment. Also, the heat generated per unit reactor volume was higher in batch reactor compared to CSTR.

This research has shown that either of the batch reactor or CSTR can be used for treatment of petroleum contaminated water environment, and the effectiveness of the Michaelis-Menten rate kinetics in bioremediation processes.

\section{REFERENCES}

1. Obire, O., \& Putheti, R. R. (2009). Fungi in bioremediation of oil polluted environments, bioremediation-pdf.
2. Hassan, M. K., \& Bashir, A. H. M. (2003, December). Determinants of Islamic banking profitability. In 10th ERF annual conference, Morocco (Vol. 7, pp. 2-31).

3. Frederickson, H. G. (1999). The repositioning of American public administration. PS: Political Science and Politics, 32(4), 701-711.

4. Eddy, P. M. (2003). U.S. Patent Application No. 29/162,944.

5. Farzadkia, M., Ghorbanian, M., Biglari, H., \& Gholami, M. (2018). Application of the Central Composite Design to Optimization of Petroleum Hydrocarbons Removal from Oil field Water using Advanced Oxidation Process, Archives of Environmental Protection, 44(4), 20 - 30.

6. Ajoku, G. A. O., \& Oduola, M. K. (2013). Kinetic model of $\mathrm{pH}$ effect on bioremediation of crude petroleum contaminated soil. 1. model development. American Journal of Chemical Engineering, 1(1), 6-10.

7. Ukpaka, C.P. (2018). Remediation of Crude oil in Loamy Soil: the Integration of Improved oil Palm Fiber (TekenaSpecies) Dried in Dark Environment, Discovery Science, 14, 65-73.

8. Levenspiel, O. (2004). Chemical Reaction Engineering (3rd Edition), Singapore: John Wiley \& Sons.

9. Chapra, S.C., \& Canale, R.P. (2010). Numerical Methods for Engineers, (Sixth Edition), New York, U.S.A.: McGraw-Hill.

10. Department of petroleum resources (DPR). (2014). Annual Statistical Bulletin. In: Ejiba, I. V., Onya, S. C., \& Adams, O. K. (2016). Impact of Oil Pollution on Livelihood: Evidence from the Niger Delta Region of Nigeria, Journal of Scientific Research \& Reports, 12(5), 1-12.

11. Cragoe, C.S. (1929). Thermodynamic Properties of Petroleum Products, U.S. Department of Commerce, Washington DC, 97.

12. Najafpour, G.D. (2007). Biochemical Engineering and Biotechnology, Oxford, U.K: Elsevier.

13. Afzal, M., Rehman, K., Shabir, G., Tahseen, R., Ijaz, A., Hashmat, A.J., \& Brix, H. (2019). Large-Scale Remediation of Oil-Contaminated Water using Floating Treatment Wetlands, Nature Partner Journal of Clean Water, 3, 1-10.

14. Ukpaka, C.P. (2019). Reactors Functional Parameters for Sodium Benzoate Production: A Comparative Study, Chemistry International, 5(2), 143-157. 